Cell Research (1998), 8, 151-158

\title{
The studies on neurogenesis induced by brain injury in adult ring dove
}

\author{
ZUO Ming XUE \\ Biology Department, Beijing Normal University, Beijing \\ 100875, China
}

\begin{abstract}
It was the first time demonstrated by us that the number of newborn neurons was increased after making lesion in forebrain of adult ring dove (Streptopelia risoria) by means of autoradiography and immunohistochemistry. Neurogenesis in the adult avian is restricted to the telencephalon. In doves with bilateral electrolytic lesion of nucleus ectostriatum (E), the mean number of proliferating cells in the lateral ventricular zone (LVZ) and newborn neurons in the forebrain increased by 1.95 times and 2.38 times respectively as compared with that in intact doves. The most remarkable increase of neurogenesis induced by nucleus ectostriatum lesions was found at the anteriorposterior level $3\left(\mathrm{~L}_{3}\right)$, where the lesion site was located. These results showed that the electrolytic brain lesion altered the distribution pattern of proliferating cells in the LVZ and resulted in increase of the number of newborn neurons in the non-VZ areas of forebrain. The changes in number and distribution pattern of proliferating cells in LVZ and newborn neurons in forebrain may be dependent on site of lesion. Studies on the relationship between proliferating cells in LVZ and newly generated neurons in non-VZ areas may help to understand the mechanism of brain plasticity and development.
\end{abstract}

Key words: Autoradiography, neurogenesis, brain lesion, ring dove.

\section{INTRODUCTION}

It is a common statement that in higher vertebrates the CNS completes neuronal 


\section{Brain lesion induced neurogenesis}

development during the pre- and prenatal periods. Preliminary work showed that neurogenesis continued in the brain of songbird during adulthood. Many newborn neurons are incorporated into the vocal-control nucleus of telencephalon, replacing old neurons and making new synaptic connections with distant targets within the forebrain[1, 2]. It is suggested that the newborn neurons in the vocal-control nucleus may play a role in the plastic modification of neuronal circuits related to song learning. The newborn neurons originate only from LVZ and migrate along the fibers of radial glial cells to their terminal fields[3, 4]. Our recent studies demonstrated that neurogenesis persists throughout adult life in the ring dove[5, 6]. The ring dove is a non-songbird, and there is no well-defined area controlling song learning and memory in the telencephalon. It implies that neurogenesis during postnatal life may be an universal phenomenon in avian. Therefore, it is possible that newborn neurons may serve functions other than those associated with song learning. It is well known that brain injury can induce reactive gliogenesis and regenesis of neuronal fibers, and new synapses were formed to help functional recovery. However, there is no report so far that the number and distribution pattern of newborn neurons can be changed after forebrain lesion in the adult bird. In a recent study in ring dove, the author suggested that reactive neurogenesis could be induced after a nucleus in hypothalamus of adult ring dove was injured. The processes of cell proliferation, migration and their final location in specific brain areas were changed after brain lesion[7]. It would be very interesting to compare the effects of brain-injury in different brain regions on proliferation, migration and differentiation of precursor neurons and to clarify if the distribution pattern of neurogenesis is region-dependent. The purpose of this work is to study the relationship between distribution of proliferating cells in LVZ and location of newborn neurons in the telencephalon in intact and brain injury birds by using combined autoradiography and immunocytochemistry. This may provide clues to understand the presence of newborn neurons in the adult avian and plasticity of CNS in the adult vertebrate brain.

\section{MATERIALS AND METHODS}

\section{Animal, surgery and treatments}

Thirty ring doves of different ages (from $10 \sim 18$ months old) were used in these experiments. All doves were bred and maintained in the indoor dove colony of the Institute of Animal Behavior, Rutgers University, USA, under a photoperiod of $12 \mathrm{~h}$ light: $12 \mathrm{~h}$ darkness (light on Am:0700 and off Pm:0700 EST). The birds were deeply anesthetized with chloropent $(0.025 \mathrm{ml} / \mathrm{kg}$, body weight) and placed in a stereotaxic instrument. The coordinates were determined by using the pigeon atlas[8] with adjustment. For all the lesion and shame birds, a teflon-insulated electrode with a diameter of $0.14 \mathrm{~mm}$ was pushed into the center of nucleus ectostriatum. A lesion was produced by passing $1.2 \mathrm{~mA}$ of anodal current, using a current meter (Grass CCU l-A), through the electrode for $40 \mathrm{~s}$. The procedure for the sham lesion animals was the same except that no electrolytic current was given. The intramuscular injection of $\left[{ }^{3} \mathrm{H}\right]$ thymidine $\left(24.79 \times 10^{10} \mathrm{~Bq} / M, 14.8 \times 10\right.$ $\mathrm{Bq} / \mathrm{g}$, body weight; England Nuclear), a marker for DNA synthesis and used as an indicator for cell proliferation was started one day after surgery for all the lesion doves. This study consists of two 
major paradigms, the short-term and long-term experiment. In the short-term experiment $(n=18)$, doves were sacrificed $1 \mathrm{~h}$ after a single $\left[{ }^{3} \mathrm{H}\right]$ thymidine injection. The birds in this group were used to observe the distribution of proliferating cells in LVZ after brain lesion. In the long-term experiment $(\mathrm{n}=12)$, each bird received a daily $\left[{ }^{3} \mathrm{H}\right]$ thymidine injection for seven days. The birds were sacrificed 3 months after the last injection. The three-month survival time allows newborn neurons migrating to final location, differentiating and developing new connections. The birds in this group were used to examine the distribution pattern of newborn neurons after brain lesion.

\section{Combined autoradiography and immunocytochemistry}

The birds were killed under deep chloropent anesthesia. Brains were fixed by intracardial perfusion with $4 \%$ paraformaldehyde in $0.1 \mathrm{M}$ phosphate buffer and embedded in polyethelyne glycol(PEG)[9]. Coronal sections ( $6 \mu \mathrm{m}$ thick) were cut on a rotary microtome and one section from every $300 \mu \mathrm{m}$ was selected for the following double-labeling steps. A cell labeled with $\left[{ }^{3} \mathrm{H}\right]$ thymidine was considered as a newly proliferated cell, but only the cell that labeled with $\left[{ }^{3} \mathrm{H}\right]$ thymidine and stained by one of neuronal specific antibodies can be identified as a newborn neuron. Three antibodies, anti-microtubule-associated protein-2 (MAP-2), anti-neuron specific nuclear protein (NeuN, from Dr. Mullen) and anti-Tau were used in these experiments for immunohistochemistry. The working solutions of MAP-2, Tau and NeuN were 1:250, 1:250 and 1:100, respectively. The working solutions for biotinylated anti-mouse IgG and $\mathrm{ABC}$ complex were 1:200 and 1:100. Antigen staining was performed using a standard ABC method. The sections were dehydrated, delipidized, coated with KODAK NTB2 nuclear track emulsion and exposed at $4{ }^{\circ} \mathrm{C}$ for $30 \mathrm{~d}$. The autoradiographs were developed and counterstained with the fluorescent DNA dye, Hoechst 33258, or cresyl violet. To test the specificity of the primary antisera used in this study, replace control experiments were performed where primary antisera were replaced by normal mouse serum. No staining was seen in the later cases.

\section{Data analysis}

All sections were mapped at a magnification of $600 \mathrm{X}$ using a computer-microscope system[10]. The criterion for a labeled cell was that it had 7 or more exposed silver grains over the nucleus, this was 10 or more times above background. The number of labeled cells was counted, and the location of labeled cells was mapped and analyzed. The data were expressed as means \pm S.D. and T-test was used to evaluate the differences between experiments.

\section{RESULTS}

\section{Short-term experiments}

The lateral ventricular zone is the only region where many proliferating cells were found. There was no labeled cell in the third, or fourth ventricular zone. In this short-term experiment, the newly proliferated cells could not complete DNA synthesis and migration within $1 \mathrm{~h}$ after $\left[{ }^{3} \mathrm{H}\right]$ thymidine injection. All newly proliferated cells were not reactive to three specific antibodies (MAP-2, Tau and NeuN) and were morphologically immature. We found that electrolytic lesion of nucleus ectostriatum promoted cell proliferation, altered both the distribution pattern and the number of proliferating cells in the LVZ. Compared with the intact birds, the mean number of proliferating cells/mm in the LVZ increased 1.95 times $1 \mathrm{~h}$ after $\left[{ }^{3} \mathrm{H}\right]$ thymidine injection. Fig 1 showed the distribution patterns of proliferating cells in the LVZ of the intact birds and the birds with electrolytic brain lesion. The anterior-posterior levels were numbered from $1\left(\mathrm{~L}^{1}\right)$ to $13\left(\mathrm{~L}^{13}\right)$ in the serise of hemisections with a lesion 
Brain lesion induced neurogenesis

site in $\mathrm{L}_{3}$. The concentration of proliferating cells varied along the anterior-posterior axis. Many more proliferating cells were distributed at $\mathrm{L}_{3}$ - $\mathrm{L}_{9}$, resching a peak of 13.23 cells $/ \mathrm{mm}$ at $\mathrm{L}_{3}$ where the lesion site was located. Fig $2 \mathrm{~b}$ showed the labeled cells with $\left[{ }^{3} \mathrm{H}\right]$ thymidine grains in $\mathrm{LVZ}$ at $\mathrm{L}_{3}$. Tab 1 showed the distribution density of proliferating cells at different brain levels of LVZ. In addition, many proliferated cells in $\mathrm{LVZ}$ were also observed at $\mathrm{L}_{1}-\mathrm{L}_{13}$ where the number of proliferating cells was very low in intact doves.

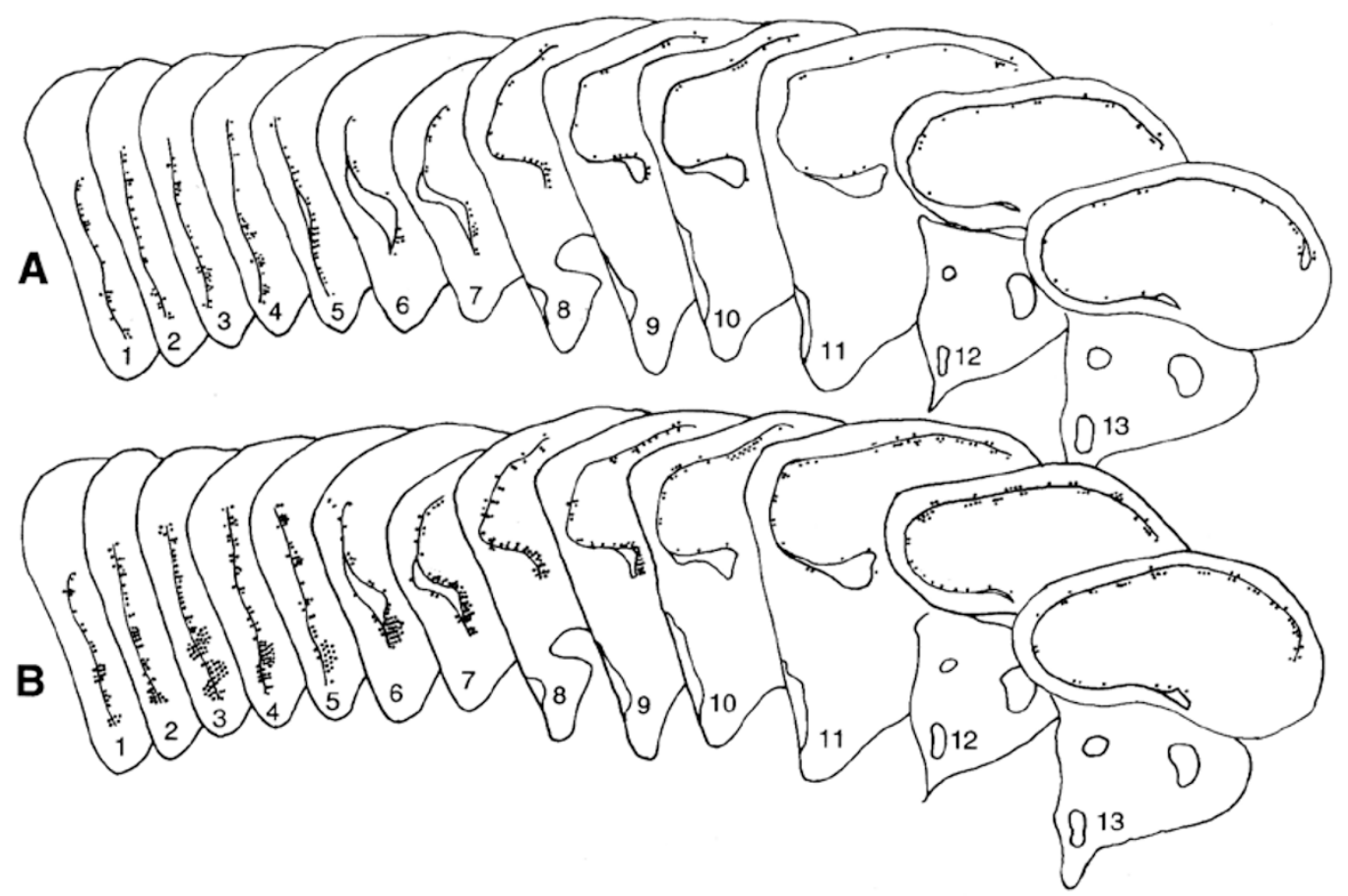

Fig 1. Distribution patterns of proliferating cells in LVZ $\left(\mathrm{L}_{1}-\mathrm{L}_{13}\right)$ of the intact birds and the birds with brain lesion. Each dot represents a labeled cell in LVZ $1 \mathrm{~h}$ after receiving a single injection of $\left[{ }^{3} \mathrm{H}\right]$ thymidine. A: control group; B: lesion group.

\section{Long-term experiments}

Electrolytic brain lesion of nucleus ectostriatum induced significant increase in the number of newborn neurons in non-VZ areas, and newborn neurons were unevenly distributed throughout the forebrain (Tab 2). No newborn neuron was found out of telencephalon.

The newborn neuron in PEG sections stained with cresyl violet had a clear large nucleus without heterochromatin in it, so that the size was larger and the nucleus was paler than that of glial cell (Fig $2 \mathrm{c}$ ). The cells immunoreactive to neuron specific antibodies and labeled by $\left[{ }^{3} \mathrm{H}\right]$ thymidine were also considered as newborn 
Tab 1. Differences in the densities of $\left[{ }^{3} \mathrm{H}\right]$ labeled cells in LVZ at different brain levels $\left(\mathrm{L}_{1}-\mathrm{L}_{13}\right)$ between the intact birds and the birds with brain lesion(cell number $/ \mathrm{mm}$ )

\begin{tabular}{|c|c|c|c|}
\hline \multirow{2}{*}{ Brain level } & \multicolumn{3}{|c|}{ Treatment } \\
\hline & Control $(n=6)$ & Lesion $(n=8)$ & Sham $(n=4)$ \\
\hline$\overline{\mathrm{L} 1}$ & $5.48 \pm 0.42$ & $8.12 \pm 0.96^{* *}$ & $5.92 \pm 0.83$ \\
\hline $\mathrm{L} 2$ & $5.29 \pm 0.75$ & $7.79 \pm 0.70^{* *}$ & $5.94 \pm 0.18$ \\
\hline L3 & $6.49 \pm 0.741$ & $3.23 \pm 1.54^{* *}$ & $6.57 \pm 0.31$ \\
\hline L4 & $5.95 \pm 0.83$ & $9.21 \pm 1.10^{* *}$ & $6.36 \pm 0.78$ \\
\hline L5 & $5.76 \pm 0.29$ & $9.64 \pm 0.93^{* *}$ & $5.81 \pm 0.35$ \\
\hline L6 & $2.91 \pm 0.22$ & $8.95 \pm 0.84^{* *}$ & $3.02 \pm 0.15$ \\
\hline L7 & $3.49 \pm 0.42$ & $8.18 \pm 0.91 * *$ & $3.33 \pm 0.47$ \\
\hline L8 & $2.97 \pm 0.55$ & $6.43 \pm 0.78^{* *}$ & $3.42 \pm 0.49$ \\
\hline L9 & $2.21 \pm 0.57$ & $8.37 \pm 0.95 * *$ & $2.79 \pm 0.53$ \\
\hline L10 & $1.73 \pm 0.86$ & $3.58 \pm 0.44^{* *}$ & $2.66 \pm 0.57$ \\
\hline L11 & $1.61 \pm 0.26$ & $3.00 \pm 0.20 *$ & $1.85 \pm 0.17$ \\
\hline L12 & $1.59 \pm 0.34$ & $2.88 \pm 0.53^{*}$ & $1.66 \pm 0.28$ \\
\hline L13 & $1.26 \pm 0.09$ & $1.90 \pm 0.39$ & $1.21 \pm 0.09$ \\
\hline total average & 3.595 & 7.021 & 3.888 \\
\hline
\end{tabular}

Tab 2. Differences in densities of newborn neurons in non-VZ areas at different brain levels $\left(\mathrm{L}_{1}-\mathrm{L}_{13}\right)$ between the intact birds and the birds with brain lesion(cell number $/ \mathrm{mm}^{2}$ )

\begin{tabular}{llllll}
\hline \multirow{2}{*}{$\begin{array}{l}\text { Brain } \\
\text { Level }\end{array}$} & Group & \multicolumn{5}{c}{ Type of section } \\
\cline { 3 - 6 } & & \multicolumn{1}{c}{ Cresyl } & \multicolumn{1}{c}{ NeuN } & \multicolumn{1}{c}{ MAP-2 } & Tau \\
\hline $\mathrm{L}_{3}$ & Control & $1.15 \pm 0.27$ & $1.05 \pm 0.10$ & $0.94 \pm 0.11$ & $0.96 \pm 0.17$ \\
& Lesion & $5.20 \pm 0.39^{* *}$ & $6.18 \pm 0.94^{* *}$ & $5.84 \pm 1.00^{*}$ & $5.16 \pm 0.73^{* *}$ \\
$\mathrm{~L}_{5}$ & Control & $1.16 \pm 0.06$ & $1.19 \pm 0.27^{* *}$ & $1.19 \pm 0.26$ & $1.23 \pm 0.23$ \\
& Lesion & $4.07 \pm 0.30^{* *}$ & $4.75 \pm 0.41^{* *}$ & $3.92 \pm 0.53^{* *}$ & $4.21 \pm 0.64^{* *}$ \\
$\mathrm{~L}_{7}$ & Control & $1.53 \pm 0.15$ & $1.45 \pm 0.14$ & $1.52 \pm 0.19$ & $1.59 \pm 0.11$ \\
& Lesion & $3.49 \pm 0.53^{* *}$ & $3.77 \pm 0.20^{* *}$ & $3.29 \pm 0.58^{* *}$ & $3.14 \pm 0.32^{* *}$ \\
$\mathrm{~L}_{9}$ & Control & $1.52 \pm 0.48^{* *}$ & $1.66 \pm 0.30$ & $1.41 \pm 0.33$ & $1.48 \pm 0.26$ \\
& Lesion & $4.40 \pm 0.53^{* *}$ & $4.75 \pm 0.51^{* *}$ & $4.41 \pm 0.83^{* *}$ & $4.91 \pm 0.63^{* *}$ \\
$\mathrm{~L}_{11}$ & Control & $2.45 \pm 0.69$ & $2.01 \pm 0.04$ & $1.40 \pm 0.31$ & $1.25 \pm 0.12$ \\
& Lesion & $3.93 \pm 0.42^{* *}$ & $4.80 \pm 0.36^{* *}$ & $4.54 \pm 0.54^{* *}$ & $4.46 \pm 0.50^{* *}$ \\
$\mathrm{~L}_{13}$ & Control & $3.33 \pm 0.83$ & $2.36 \pm 0.26$ & $2.27 \pm 0.43$ & $2.83 \pm 0.49$ \\
& Lesion & $5.48 \pm 0.85^{* *}$ & $6.12 \pm 0.57^{* *}$ & $6.07 \pm 0.54^{* *}$ & $5.82 \pm 0.49^{* *}$ \\
\hline In & Control & 1.856 & 1.620 & 1.455 & 1.557 \\
average & lesion & 4.420 & 5.060 & 4.678 & 4.617 \\
\hline
\end{tabular}

${ }^{*} \mathrm{P}<0.05 ;{ }^{* *} \mathrm{P}<0.01$

Cresy1: the cells stained with cresyl violet; NeuN, MAP-2, Tau: cells labeled with $\left[{ }^{3} \mathrm{H}\right]$ thymidine were also immunoreactive to one of the neuron specific antibodies.

neurons (Fig 2d, e, f). Compared with intact birds, the distribution pattern of newborn neurons in non-VZ area was changed after lesioning of the nucleus ectostriatum. The number of newborn neurons increased singificantly throughout the entire telencephalon. The most remarkable increase of newborn neurons in non-VZ 
area were found at brain level $\mathrm{L}_{3}$, where the number of newborn neurons was 4.52 times as high as that of intact birds. In addition, many newborn neurons were also distributed in the medial to caudal neostriatum at brain level $\mathrm{L}_{13}$ where a few new born neurons were found in intact birds.
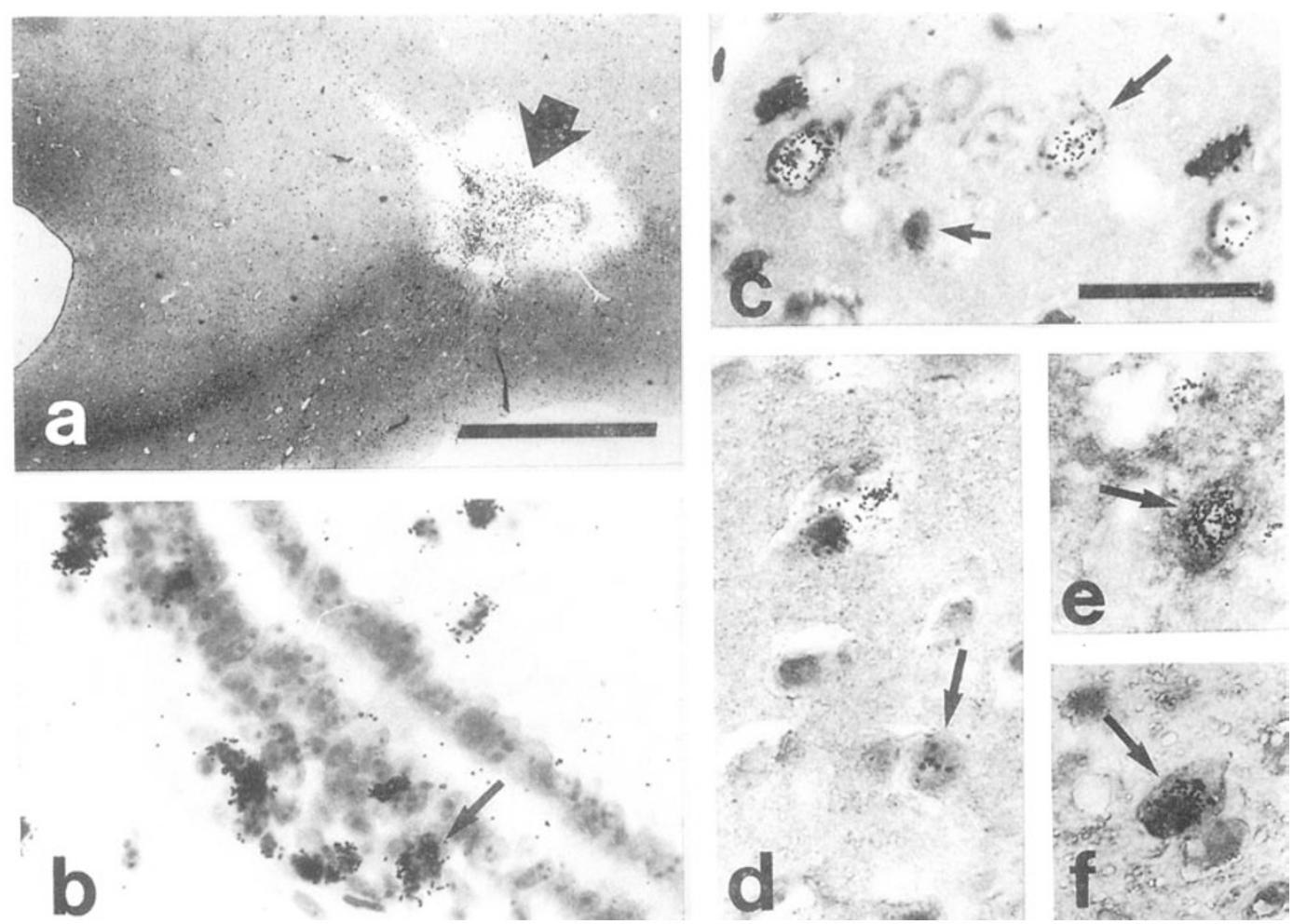

Fig 2. Photomicrographs of coronal sections depicting the $\left[{ }^{3} \mathrm{H}\right]$-labeled cells in the LVZ and newborn neurons in the non-VZ areas. a: Arrow showing the lesion site in nucleus ectosriatum. b: Cells labeled in LVZ. c: Cresy1-staining section showing the neurons (long arrow) and glia cells (short arrow). d-f: sections showing the double-labeled neurons (arrows) by $\left[{ }^{3} \mathrm{H}\right]$ thymidine and immunohistochemical staining of Tau (d), MAP-2 (e) and NeuN (f). Bar $=30 \mu \mathrm{m}$.

\section{DISCUSSION}

Our previous work demonstrated that electrolytic lesion of the nucleus ventromedial hypothalamus (VMN), a nucleus in hypothalamus of ring dove, promoted neurogenesis[7]. The present results extend this finding to the region of telencephalon in the ring doves, indicating that forebrain lesion not only induces the increase of newborn neurons but also alters the distribution pattern of both proliferating cells in LVZ and newborn neurons in non-VZ areas. The results in this experiment also 
showed that sham lesion did not have this effect.

Although the lesion of both VMN and nucleus ectostriatum resulted in a large number of labeled proliferating cells and newborn neurons in the telencephalon, the distribution pattern resulted by lesion of different brain regions were significantly different. In short-term experiments, for example, the highest density of proliferating cells in LVZ after the lesion of nucleus ectostriatum was found in the anterior pole of telencephalon at level $\mathrm{L}_{3}$ where lesion site was located. In the cases of VMN lesion, however, although the highest density of proliferating cells was also found in the same region of brain at level $\mathrm{L}_{3}$, the most remarkable increase of proliferating cells was found in neostriatum caudale (NC) at level $\mathrm{L}_{12}-\mathrm{L}_{13}$, where the proliferating cells were respectively 2.93 and 3.56 times more compared with that of intact birds. In intact birds, the neostriatum caudale is one of the regions where very few proliferating cells in LVZ are located.

In long-term experiments, the effects of lesions of the nucleus ectostriatum appear to be stronger than that in the birds received VMN lesion. Compared with the lesion of VMN, several areas in the telencephalon after lesions in the nucleus ectostriatum had particularly high density of labeled neurons, including regions such as lobus parolfactorius (LPO) at level $\mathrm{L}_{3}-\mathrm{L}_{4}$, hyperstriatum ventrale, and neostriatum caudale at level $\mathrm{L}_{11}-\mathrm{L}_{13}$, but most remarkable increase of newborn neurons was in the region of LPO at level $\mathrm{L}_{3}$ where there were very few newborn neurons in intact birds. In the cases of the birds having VMN lesion, the density of labeled neurons increased gradually from anterior to posterior telencephalon, reaching a peak in the neostriatum caudale at level $\mathrm{L}_{13}$, where the density was 2.30 times higher than that at level $\mathrm{L}_{3}$. In all our experiments, no matter where the lesion site was located, the vast majority of newborn neurons was found in the region adjacent to the lesion site. The present data suggests that the effects of brain lesions which altered the distribution pattern of nerogenesis may be region-dependent.

Previous evidence showed that the commitment of most newborn neurons to their final location occurs in the ventricular zone of higher vertebrate during the embryonic stage[11]. In songbird, newborn neurons originate from LVZ and then migrate and invade most regions of the telencephalon during postnatal life[l, 12]. The patterns of migration and location of newborn neurons in non-songbird are similar to that in songbird[5]. The results of our previous experiments also suggest that in ring dove newborn neurons may originate from LVZ and migrate to different brain regions during postnatal life. In the present experiments, we found that the distribution patterns of labeled proliferating cells both in LVZ and in non-VZ areas were significantly changed after brain lesion. In normal adult songbird, the highest concentration of proliferating cells was found in ventral portion of the brain at level $\mathrm{L}_{3}$, a region with high rates of cell division and was termed as "proliferative hot spots". Precursors of newborn neurons may originate from this region in adult songbird as some authors suggested[12]. A very interesting finding of this study is that after brain lesion the highest density of both proliferating cells in LVZ and 


\section{Brain lesion induced neurogenesis}

newborn neurons in non-VZ area occurred at the same level of $\mathrm{L}_{3}$, i.e. the "hot spots" in the song bird. However, little is known about the relationship between the site of origin and the final destination of newborn neurons, and how the newborn neurons changed their migrating pathways and terminated in specific brain regions after brain lesions. The present data from our experiments of lesioning both VMN and nucleus ectostriatum showed that there were parallel changes between cell proliferation in the LVZ and neurogenesis in the telencephalon. These parallel changes may support indirectly that newborn neurons originate from LVZ and migrate to distant locations in the forebrain[13]. The newborn neurons occurred during adult life could be of particular interest for further research not only in histogenesis but also in neural plasticity.

\section{ACKNOWLEDGEMENTS}

I would like to thank Dr. Cheng of Institute of Animal Behavior, Rutgers University, USA, for her advice and help during my experiments. This work was supported by the National Natural Science Foundation of China, Grant No. 39570250.

\section{REFERENCES}

[1] Goldman SA, Nottebohm F. Neuronal production, migration, and differentiation in a vocal control nucleus of the adult female canary brain. Proc Natl Acad Sci 1983;80:2390-4.

[2] Paton JA, Nottebohm F. Neurons generated in the adult brain are recruited into functional circuits. Science 1984; 225:1046-8.

[3] Alvarez-Bulla A, Nottebohm F. Migration of young neurons in adult avian brain.Nature 1988; 335:353-4.

[4] Nordeen KW, Nordeen EJ. Projection neurons within a vocal motor pathway are born during song learning in zebra finches. Nature 1988;334:149-51.

[5] Zuo MX. The newborn neurons in the brain of adult ring dove. Science Bulletin China 1995; 40:1133-6.

[6] Ling CY, Zuo MX, Alvarez-Buylla A, Cheng MF. Neurogenesis in Juvenile and adult ring doves. J Comp Neurol 1997; 379:300-12.

[7] Zuo MX. The effects on neurogenesis induced by brain injured of nucleus ventromedialis hypothalami in the brain of adult ring dove. Acta Physiologica Sinica, 1996; 48:209-14.

[8] Karten HJ, Hodos W. A Stereotaxic atlas of the brain of the pigeon (Columba livia). The John Hopkins Press: Baltimore Maryland 1967: 31-256.

[9] Zuo MX. Application and technique of embedding animal tissue with polyethelyne glocol. J BJ Nor Univ (Nat Sci) 1996; 32:271-3.

[10] Alvarez-Bulla A, Vicario DS. Simple microcomputer system for mapping tissue sections with the light microscope. J Neurosci Meth 1988; 25:165-73.

[11] Rakic P. Specification of cerebral cortical areas. Science 1988; 240:170-6.

[12] Alvarez-Buylla A, Theelen M, Nottebohm F. Proliferation "hot spots" in adult avian ventricular zone reveal radial glia cell divisions. Neuron 1990; 5:101-9.

[13] Kirn JR, Nottebohm F. Direct evidence for loss and replacement of projection neurons in adult canary brain. J Neurosci 1993; 13:1654-63.

Received Feb-11-1998. Revised March-16-1998. Accepted March-25-1998. 